\title{
The Distinguish Method of the Different Sand Types in the Accurate Geologic Research Static Data-Base
}

\author{
Hou Pengfei ${ }^{1}$ Zhao Zhongbo ${ }^{2} \quad$ Wu Yanju ${ }^{3}$ \\ 1. College of earth science of Northeast Petroleum University, Daqing, Heilongjiang, China, 163318 \\ 2,3. No. 1 Oil Production Plant, Daqing Oilfield Company,163001
}

\begin{abstract}
We choose sand types needed in the geologic reserves accurate calculation as an example, and discuss the sand types distinguish method in the accurate geologic research static data-base, then give the distinguish method of different sand types .Based on this method, we can pick up different sand types thickness parameters form the accurate geologic research static data-base, and we can also do the geologic reserves accurate calculation of different sand types.
\end{abstract}

Key Words: Static data-base Sand type Sediment unit Effective thickness Geologic reserves

\section{FOREWORD}

Static database fine geologic research, also known as static database subdivided sedimentary unit, is one of the fields of fine geologic research. In the process of oilfield development and production or fine geologic research, the description of the characteristics of sand body distribution, or to build three-dimensional geological model, or in reservoir numerical simulation, or fine geological reserves calculation ${ }^{[1]}$, the static database of fine geologic studies are needed to determine sand body types. However, due to continental basin inland water back frequently, fluvial delta deposition is obvious cyclicity ${ }^{[2]}$, vertical multi-layer sandstone are overlapped each other, cause every single sand body types may be put in a variety of circumstances, give us correctly identify every single sand body types difficult.

This paper needs to be fine calculation of geologic reserves of sand body types (channel and non channel thick and thin sand body, class I table outside and graded sand body, class II table outside and graded sand body) as an example, discusses the static fine geologic research database sand body type identification method.

Fine geologic static database fields related to the sand body types are: Jh (well), Dymc (unit name), Xb (phase contrast), Syds (sandstone top depth), Syhd (sandstone thickness), Yxds (effective top), Yxhd (effective thickness), Elsyds (second sandstone roof deep), Elsyhd (second class sandstone thickness).

\section{THE CHANNEL, THE CHANNEL SAND BODY OF DISCRIMINATION}

Channel with the channel sand body all belong to the industrial production capacity of oil and gas reservoir of the part of the thickness of sand body, which is the effective thickness of the sand body.

\subsection{The channel sand body and the channel sand body of discrimination}

Channel sand bodies and non river sand bodies can be distinguished by $\mathrm{Xb}$ (phase contrast) field. Corresponding to the Yxhd (effective thickness) of more than 0 of the unit, if the $\mathrm{Xb}$ (phase) field is " $\mathrm{H}$ ", it is the river sand body, if the $\mathrm{Xb}$ (phase) field is empty, it is not the river sand body.

2.2 The thick and thin layer of sand body of discrimination

The boundary between the thick layer and the thin layer is 0.4 , that is, the effective thickness is greater than or equal to 0.4 meters is thick layer, for the thin layer is less than 0.4 meters. Specific criteria are as follows:

(1)There is only one effective thickness record in one unit.

According to the thickness of the effective thickness, thin lines (0.4) can be judged.

(2) There are a number of effective thickness records within one unit.

First calculate the thickness of the sandwich, and then further subdivided according to the thickness of the layer. If the thickness of the interlayer is greater than or equal to 0.4 meters, according to the thickness of each of the respective boundaries of classification. If the thickness of the layer is less than 0.4 meters, the following conditions may occur:

(10f the mezzanine above and below the effective thickness has a greater than or equal to 0.4 meters or interlayer thickness equal to 0 (due to water flooded layer interpretation and permeability interpretation and the effective thickness of layer separated to represent), then combine the effective thickness together above and below , then according to the thickness of boundary classification. 
2lf the thickness of the above and below the layer is less than 0.4 meters, the effective thickness of the upper layer and the lower layer is separately classified according to the thickness of the layer.

\section{OFF-BALANCE SHEET SAND BODY TYPES OF DISCRIMINATION}

Off-balance sheet sand body is that part of the industrial capacity of oil and gas reservoir thickness of sand body. Divided into Ioff-balance-sheet independence and gradient, II off-balance sheet sand body independence and gradient sand body.

3.1 Discrimination of the same sand body

In sedimentary unit division and correlation of the process, in order to take care of the needs of the region comparison. Sometimes, the same sand body split into two units, in judgement of the type of sand body, need to the two unit as a sand body to consider, not only consider the single sand body types.

The distinction between the upper and lower adjacent two units of the sand body is a sand body, only need to judge whether the two types of sandstone roof is connected to the bottom of the. That is to judge the first unit of the two types of sandstone top depth + two type of sandstone thickness and the next element of the two types of sandstone top depth is equal, if the two equal, it is a sand body, otherwise, it is two sand bodies.

3.2 The off-balance sheet sand body types of discrimination

First of all, to determine whether the upper and lower two units is a sand body.

(1) if it is not a sand body, the following method is used to determine,

$\left\{\begin{array}{l}\text { Last unit Elsyhd }>0 \text {, Syhd }=0, \text { Yxhd }=0 \\ \text { Next unit Elsyhd }>0 \text {, Syhd }=0 \text {, Yxhd }=0\end{array}\right.$ Elsyhd are Type Igradient.

2lff $\left\{\begin{array}{l}\text { Last unit Elsyhd }>0 \text {, Syhd }>0 \text {, Yxhd }=0 \\ \text { Next unit Elsyhd }>0 \text {, Syhd }=0 \text {, Yxhd }=0 \text {, then the last unit Syhd is Type Igradient, then }\end{array}\right.$ the next unit Elsyhd is Type Igradient; if last unit Elsyhd-Syhd $>0$, then the lastunit Elsyhd-Syhd is Type Igradient.

3)f $\left\{\begin{array}{l}\text { Last unit Elsyhd }>0 \text {, Syhd }>0 \text {, Yxhd }>0 \\ \text { Next unit Elsyhd }>0 \text {, Syhd }=0 \text {, Yxhd }=0 \text {, then the last unit will appear two situations: }\end{array}\right.$

When Elsyhd-Syhd=0, If Syhd-Yxhd=0, the last unit does not off-balance sheet, the next unit Elsyhd is Type Igradient; If Syhd-Yxhd $>0$,then the last unit Syhd-Yxhd and the next unit Elsyhd are Type Igradient 。

If Elsyhd-Syhd $>0$, then the Elsyhd-Syhd is the last unit Type Igradient, Syhd-Yxhd is the last unit Type Igradient, the next unit Elsyhd is Type Igradient;

4lff $\left\{\begin{array}{l}\text { Last unit Elsyhd }>0 \text {, Syhd }=0 \text {, Yxhd }=0 \\ \text { Next unit Elsyhd }>0 \text {, Syhd }>0 \text {, Yxhd }=0\end{array}\right.$ then the last unit Elsyhd is Type Igradient, If Elsyhd-Syhd $>0$, the next unit Elsyhd-Syhd is Type Igradient.

5Df $\left\{\begin{array}{l}\text { Last unit Elsyhd }>0 \text {, Syhd }=0 \text {, Yxhd }=0 \\ \text { Next unit Elsyhd }>0 \text {, Syhd }>0 \text {, Yxhd }>0\end{array}\right.$ ext unit will appear two situations:

When Elsyhd-Syhd=0, if Syhd-Yxhd=0,then the next unit does not off-balance sheet; if Syhd-Yxhd $>$ 0 , then the next unit Syhd-Yxhd is Type Igradient;

When Elsyhd-Syhd $>0$, Elsyhd-Syhd is the next unit Type Igradient, Syhd-Yxhd is the next unit Type Igradient.

6lf $\left\{\begin{array}{l}\text { Last unit Elsyhd }>0 \text {, Syhd }>0 \text {, Yxhd }=0 \\ \text { Next unit Elsyhd }>0 \text {, Syhd }>0 \text {, Yxhd }=0, \text { Two situations will appear: }\end{array}\right.$

For the last unit, if Elsyhd-Syhd=0, Syhd is Type Igradient; then the nextunit Syhd is Type Igradient, if next unit Elsyhd-Syhd $>0$, then thenext unit Elsyhd-Syhd is Type Igradient;

For the last unit, when Elsyhd-Syhd $>0$, then the Elsyhd-Syhdis the last unit Type Igradient, Syhd is Type Igradient, then the next unit Syhd is Type Igradient; If the next unit Elsyhd-Syhd $>0$, the next unit Elsyhd-Syhd is Type Igradient 。 


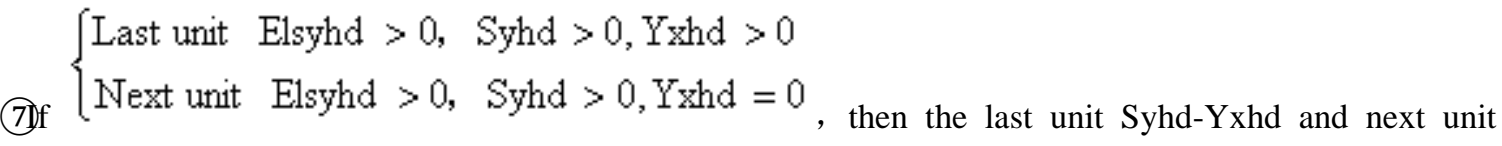
Syhd are Type Igradient, two situations will appear,

For the last unit, if Elsyhd-Syhd=0,then the next unit Elsyhd-Syhd is Type Igradient;

For the last unit, if Elsyhd-Syhd $>0$, then Elsyhd-Syhd is Type Igradient, now for the next unit, if Elsyhd-Syhd $>0$, then Elsyhd-Syhd is Type Igradient.

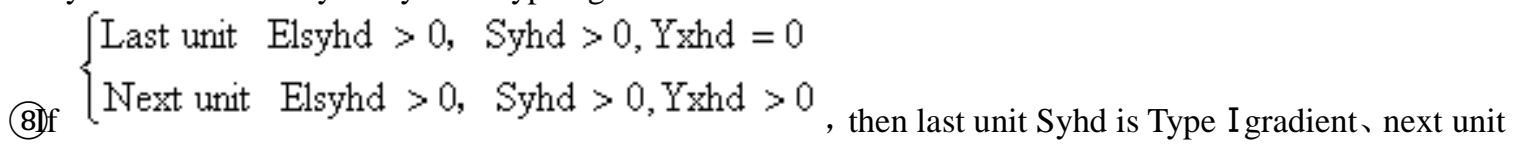
yhd-Yxhd is Type Igradient, two situations will appear,

For the next unit, if yhd-Syhd=0,then, Last unit Elsyhd-Syhd is Type Igradient

For the next unit, if Elsyhd-Syhd $>0$,then Elsyhd-Syhd is Type Igradient, now for the last unit, if Elsyhd-Syhd $>0$, then Elsyhd-Syhd is Type Igradient.

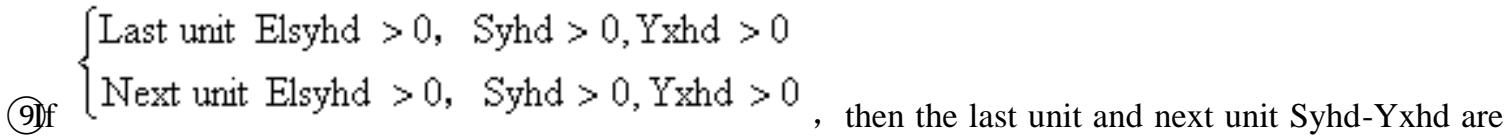
Type Igradient, two situations will appear,

For the last unit, when Elsyhd-Syhd=0,then if the next unit Elsyhd-Syhd $>0$, the Elsyhd-Syhd is Type Igradient.

For the last unit, if Elsyhd-Syhd $>0$, then Elsyhd-Syhd is Type Igradient, and for the next unit, if Elsyhd-Syhd $>0$, Elsyhd-Syhd is Type IIgradient.

\section{APPLICATION}

According to the different types of sand body identification method, We developed a corresponding static database handler.Extract different kinds of sand body basic data from the fine geological research database, using geologic reserve computation method[1], calculates the different kinds of sand body geologic reserves the block of Daqing Oilfield in Saertu and Putaohua oil formation (Table 1), Find out the different types of sand body in the block geological reserves, Provides a reliable geological basis for further tap production potential. Application results show that, The above method can be accurately extracted from the study of fine geology static database parameters of different types of sand body thickness, at present the method has been in production for the popularization and application.

Table 1 the different sand type's geological reserves distributing table of Saertu and Putaohua oil formation of some block in Daqing oil field

\begin{tabular}{|c|c|c|c|c|c|c|c|c|}
\hline & $\begin{array}{c}\text { Thick } \\
\text { reservoir } \\
\text { group }\end{array}$ & $\begin{array}{c}\text { Thin } \\
\text { channel } \\
\text { sand } \\
\text { body }\end{array}$ & $\begin{array}{c}\text { river } \\
\text { channel } \\
\text { sand body }\end{array}$ & $\begin{array}{c}\text { Non-thick } \\
\text { river } \\
\text { channel } \\
\text { sand body }\end{array}$ & $\begin{array}{c}\text { Non-Thin } \\
\text { river } \\
\text { channel } \\
\text { sand body }\end{array}$ & $\begin{array}{c}\text { Type I } \\
\text { gradient }\end{array}$ & $\begin{array}{c}\text { Type I } \\
\text { independent }\end{array}$ & $\begin{array}{c}\text { Type II } \\
\text { gradient } \\
\text { independent }\end{array}$ \\
\hline S I & 345.042 & 1.103 & 362.517 & 68.82 & 84.944 & 46.947 & 14.28 & 113.399 \\
\hline S II & 2279.387 & 20.505 & 929.696 & 179.808 & 269.33 & 96.092 & 30.342 & 222.899 \\
\hline SIII & 423.817 & 2.213 & 532.645 & 115.119 & 139.088 & 80.507 & 26.633 & 173.118 \\
\hline P I & 205.358 & 0.952 & 295.175 & 66.625 & 62.154 & 25.96 & 6.623 & 54.575 \\
\hline P II & 1010.917 & 3.54 & 464.79 & 82.892 & 115.283 & 37.463 & 15.5 & 95.257 \\
\hline
\end{tabular}

unit: ten thousand ton

\section{REFERENCES}

[1] Liu Jiyu,Sui Xinguang,Yu Runtao.Method of fine calculation of geologic reserves[J].Marine Geology Letters ,2003,19(9):31-34;

[2] Liu Dingzeng, Wang Qimin, LI Bohu. Development of multi layer sandstone oil field in Daqing [M], Beijing:Peotroleum lndustry Press, 1996. 